\title{
Enriched Mechanical Properties of Epoxy/Coir Fiber Composites with Graphene Oxide
}

\section{ISSN: 2576-8840}

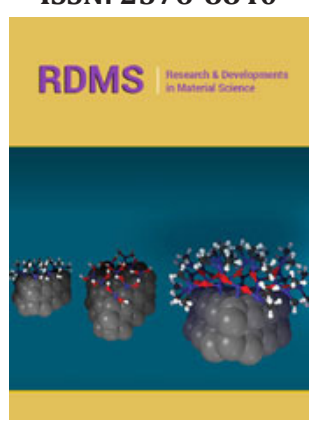

*Corresponding author: Satyendra Mishra, Kavayitri Bahinabai Chaudhari North Maharashtra University, Jalgaon-425001, MS, India

Submission: 海 May 10, 2019

Published: 㘹 May 15, 2019

Volume 10 - Issue 5

How to cite this article: Preetam S B, Satyendra $\mathrm{M}^{*}$. Enriched Mechanical Properties of Epoxy/Coir Fiber Composites with Graphene Oxide. Res Dev Material Sci. 10(5).RDMS.000749.2019.

DOI: 10.31031/RDMS.2019.10.000749

Copyright@ Satyendra Mishra, This article is distributed under the terms of the Creative Commons Attribution 4.0 International License, which permits unrestricted use and redistribution provided that the original author and source are credited.

\author{
Preetam S Bharadiya and Satyendra Mishra* \\ Kavayitri Bahinabai Chaudhari North Maharashtra University, Jalgaon-425001,MS, India
}

\begin{abstract}
Synthesis of Graphene oxide (GO) was done by Improved hummer's method and confirmed by Field Emission Scanning Electron Microscopy, Transmission Electron Microscopy, Fourier Transform Infrared Spectroscopy, X-ray Diffractometry and Raman Spectroscopy. The dispersion of GO was obtained using cetyl trimethyl ammonium bromide (CTAB), a cationic surfactant, in the epoxy matrix. The enrichment in the mechanical properties was observed by loading of GO (1.0 wt.\%, $2.5 \mathrm{wt} . \%$ and $5.0 \mathrm{wt} . \%)$ in the epoxy/coir fiber (ECF) composites. The ECF composites were prepared using hand layup technique, with constant fiber ratio of $5.0 \mathrm{wt}$. \% and fiber length in the range of $5-7 \mathrm{~mm}$. The highest tensile strength of 13 $\mathrm{MPa}$ was obtained for $5.0 \mathrm{wt}$ \% GO-reinforced ECF as compared to $4 \mathrm{MPa}$ for neat epoxy and $6 \mathrm{MPa}$ for ECF. Flexural strength of $64 \mathrm{MPa}$ was obtained for $5.0 \mathrm{wt}$. \% GO reinforced ECF as compared to $23 \mathrm{MPa}$ for neat epoxy and $32 \mathrm{MPa}$ for ECF. The impact strength increased from $31 \mathrm{~J} / \mathrm{m}$ to $44 \mathrm{~J} / \mathrm{m}$ and $135 \mathrm{~J} / \mathrm{m}$ for neat epoxy, ECF, and $5.0 \mathrm{wt}$ \% GO reinforced ECF respectively. It was noticed that the CTAB treatment resulted in proper interaction of GO with epoxy resin and coir fibers, which improved mechanical properties of ECF.
\end{abstract}

Keywords: Coir fiber; Graphene oxide; Epoxy; Mechanical

\section{Introduction}

Epoxy resin is a versatile high-performance thermosetting polymer. Due to its higher strength and ease of processability; epoxy resin finds applications in aerospace sector, automobile sectors [1], in coatings [2], for electronic encapsulation, as adhesives [3], hybrid composites [4]. However, epoxy resin alone cannot provide good strength suitable for highperformance applications because of its inherent hard and brittle nature [5]. Therefore, epoxy resin has to be mixed or modified by nanomaterials such as Graphene oxide, Graphite nanoplatelet and Graphene and/or with natural or synthetic fiber as a reinforcing agent [6-9] to improve its stiffness and strength [10-16].

Among the different synthetic fibers, glass and carbon fibers are mostly used due to higher enhancement in mechanical properties of the epoxy resin, suitable for high-performance applications. However, these synthetic fibers are expensive, non-recyclable, non-renewable, non-biodegradable in nature, and toxic products are released during their production. So, these fibers create major environmental hazards. As compared to synthetic fibers, natural fibers are cheaper, lower in density, biodegradable [17,18], and when incorporated after chemical modifications enhances the electrical [19], mechanical [20-22], and water absorption properties $[23,24]$ of various polymers. Among the different natural fibers, coir fiber, a waste material of the coconut husk having higher toughness and durability, finds applications in various products such as ropes, mattresses, baskets, brushes, automobile parts and ballistic appliances [25-27]. The higher strength of coir fiber as compared to majority of the natural fiber makes it suitable for enriching the mechanical properties of epoxy resin. However, the higher lignin percentage in its structure makes it poorly compatible with the epoxy resin. But certain chemical or physical treatment can enhance the adhesion of coir fiber with the epoxy resin. Also, when coir fibers are used as reinforcing agent along with nanomaterials then it will enhance the mechanical properties of the epoxy resin due to higher strength of coir fibers and higher surface area of nanomaterials [28-31].

Among the different nanomaterials, Graphene oxide (GO) has attracted major world attention owing to its ease of aqueous processability obtained by the presence of oxide 
functional groups such as epoxide, carbonyl and carboxyl as defects [32-36]. Due to promising mechanical, thermal and electronic properties [37-40], GO finds applications in drug delivery [37], photo catalysis, composites, gas sensing, energy storage, super capacitors, etc [38,39]. But the major drawback is that GO has poor dispersion and weak interfacial adhesion with epoxy resin and coir fiber due to formation of agglomerates among GO sheets
[41]. In order to overcome this problem, GO is pretreated with a cationic surfactant, cetyl trimethyl ammonium bromide (CTAB) and this mixture is simultaneously dispersed in the epoxy/coir fiber matrix (Figure1). Epoxy/coir fiber (ECF) composites with GO concentrations of $1.0 \mathrm{wt}$. \%, $2.5 \mathrm{wt}$. \% and $5.0 \mathrm{wt}$. \% individually are prepared by hand layup technique and their enriched mechanical properties are also addressed in this study.

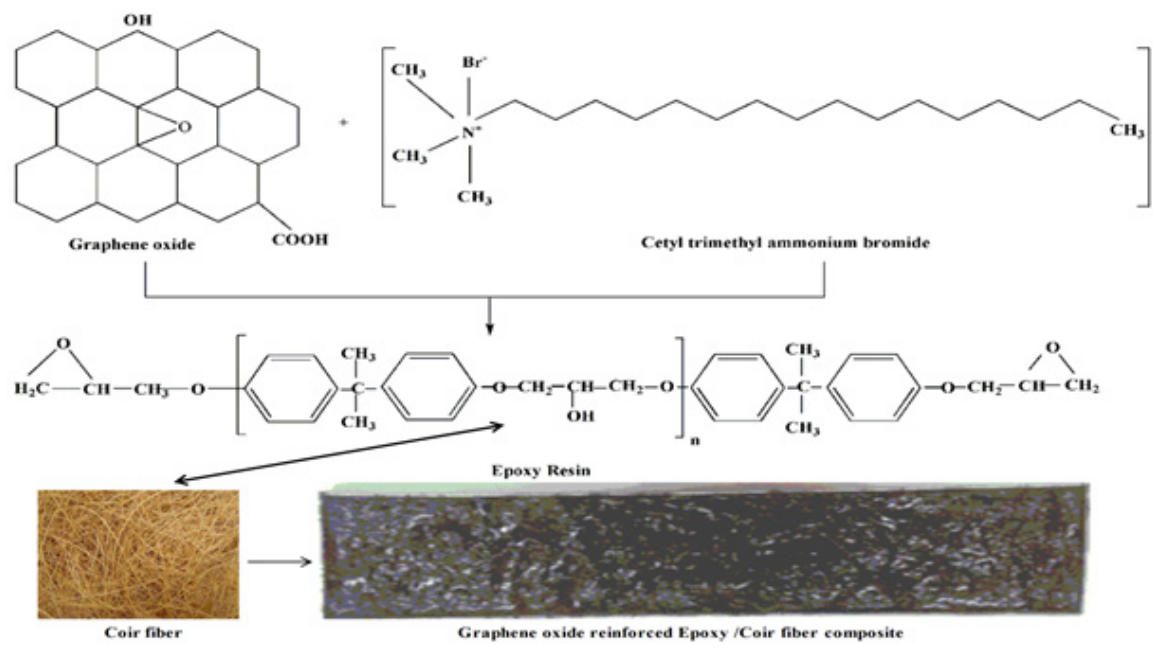

Figure 1: Schematic representation of preparation of GO reinforced Epoxy/coir fiber composite.

\section{Experimental Section}

\section{Materials}

Graphite powder, Hydrogen peroxide (30\%) and Methanol were purchased from S D Fine chemicals, Mumbai, India. Cetyl trimethyl ammonium bromide (CTAB), Sulphuric acid, Orthophosphoric acid, Hydrochloric acid, Potassium permanganate (99.9\%), Polyvinyl Alcohol (PVA), Ethanol and Petroleum Ether were purchased from Merck chemicals, Mumbai, India. Epoxy Resin LY556 and Hardner HY951 were purchased from Variety Plywood, Mumbai, India. All the chemicals were used without further purification. All experiments were carried out with doubled distilled water.

\section{Extraction of coir fiber}

The Coconut Husk was dried under the sun. The coir fibers were collected manually after soaking the husk in hot water to lose the interaction between fiber and lignocellulosic matrix and drying at $40{ }^{\circ} \mathrm{C}$.

\section{Synthesis of GO and fabrication of GO reinforced epoxy/ coir fiber composites (GO/ECF)}

GO was synthesized by Improved Hummer's method mentioned elsewhere [42-44] and GO reinforced epoxy/coir fiber composites were fabricated using hand layup technique as mentioned in our earlier work [45]. $1 \mathrm{~g}$ of CTAB was added to $100 \mathrm{ml}$ of methanol followed by addition of $2 \mathrm{~g}$ GO powder. This mixture was dispersed ultrasonically using bath sonicator for $3 \mathrm{~h}$ followed by addition of $200 \mathrm{~g}$ of epoxy resin with continuous stirring for proper mixing. The methanol was removed completely from this mixture by keeping it in an oven at $50{ }^{\circ} \mathrm{C}$ and further brought down to room temperature. Later on, $10 \mathrm{~g}$ of coir fibers (size 7-9mm) were added in this mixture for $1 \mathrm{~h}$ by glass rod followed by mixing of hardener in a ratio of 10:1.
This mixture was spread into the mold (270mm x 50mm x 5mm), by hand layup technique. A thin film of $5 \%$ aqueous solution of PVA was used as a mold releasing agent. The mold was closed with its core and kept for 7 days for curing at one atmospheric pressure and room temperature (approx. $31^{\circ} \mathrm{C}$ ). The cured composite was removed and cut according to the desired specimen size and shape.

\section{Characterization of GO and GO/ECF}

The morphology of the GO was investigated on Field Emission Scanning Electron Microscope (FE-SEM, Model S-4800 Type II Hitachi High Technology Corporation Limited, Japan), operated at $15.0 \mathrm{KeV}$, and also on Transmission Electron Microscope (TEM, Philips CM-200, Eindhoven, The Netherlands) with $75 \mu$ A of filament current and $200 \mathrm{KV}$ of accelerating voltage .

The functional groups of the GO were analyzed by Fourier Transform Infrared Spectroscopy (FTIR, Model-8400 Shimadzu, Japan) with a resolution of $4 \mathrm{~cm}^{-1}$, over the frequency range of 400 $4000 \mathrm{~cm}^{-1}$. Each spectrum is average of 100 scans. The samples were prepared by mixing the powdered GO with powdered potassium bromide and pressing it under high pressure.

The crystallinity and structural behavior of the GO were determined by X-Ray Diffractometer (XRD) (D8 Advance Bruker) Limited Germany using monochromatic $\mathrm{CuK} \alpha 1$ radiation $(\lambda$ $=1.5406 \AA$ ) at $40 \mathrm{kV}$ and $40 \mathrm{~mA}$. The diffraction patterns were optimized with a step size of 0.020 over an angular range 5-80응 (20) with a scanning speed of 10 s. Raman spectra of the GO were recorded on a Raman Spectrometer (Horiba JY LabRAM HR 800 ) coupled with microscope in reflectance mode with $633 \mathrm{~nm}$ excitation laser source and a spectral resolution of $0.3 \mathrm{~cm}^{-1}$.

Mechanical properties of GO/ECF composites were performed on Universal Testing Machine, Model UT2302, HI-TECH Instrument 
and services, Mumbai at cross-head speed of $50 \mathrm{~mm} / \mathrm{min}$. The tensile test was carried out according to ASTM D3039. For the tensile strength, width, length and thickness of the specimens were kept as $25 \mathrm{~mm}, 250 \mathrm{~mm}$ and $3 \mathrm{~mm}$ respectively. The tensile strength and Youngs modulus are expressed using the equation, $\sigma_{\mathrm{t}}=\mathrm{P}_{\max }$ $/ \mathrm{A}$ and $\mathrm{E}=\Delta \sigma / \Delta \varepsilon$ respectively, where $\sigma_{\mathrm{t}}=$ tensile strength $(\mathrm{MPa})$, $\mathrm{P}_{\max }=$ maximum force before failure $(\mathrm{N}), \mathrm{A}=$ average cross-sectional area $\left(\mathrm{mm}^{2}\right), E=$ Young's modulus of elasticity (MPa), $\Delta \sigma=$ difference in applied stress between the two strain points (MPa), $\Delta \varepsilon=$ difference between two strain points.

The three-point flexural tests of the composites were conducted using the same UTM according to ASTM D790. The specimen dimensions were $12.7 \mathrm{~mm} \times 125 \mathrm{~mm} \times 3.2 \mathrm{~mm}$. The flexural strength and flexural modulus were calculated using formula $\sigma_{\mathrm{f}}=3 \mathrm{PL} / 2 \mathrm{bd}^{2}$ and $E_{\mathrm{f}}=\Delta \sigma_{\mathrm{f}} / \Delta \varepsilon_{\mathrm{p}}$, respectively, where $\sigma_{\mathrm{f}}=$ stress at the outer surface at mid span (MPa), $\mathrm{P}=$ applied force $(\mathrm{N}), \mathrm{L}=$ support span $(\mathrm{mm})$, $\mathrm{b}=$ width of the specimen $(\mathrm{mm}), \mathrm{d}=$ thickness of the specimen $(\mathrm{mm})$,

\section{Results and Discussions}

\section{Morphological, structural and functional properties of G0}

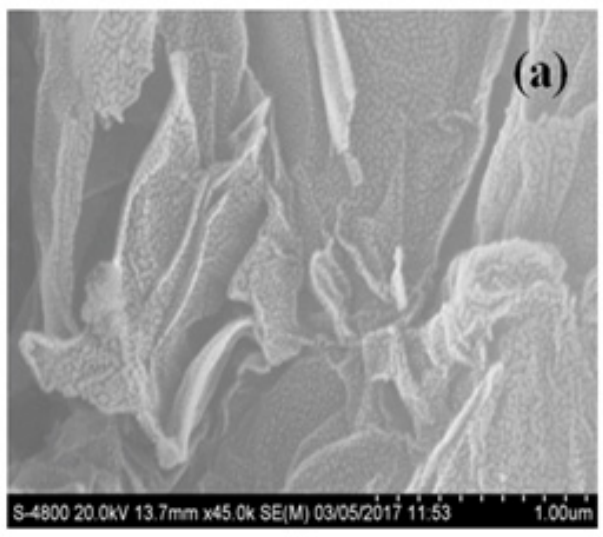

Figure 2: a) FE-SEM and b) TEM images of Graphene oxide.

Figure $2 \mathrm{a} \& 2 \mathrm{~b}$ shows the FE-SEM and TEM images of the GO showing folded sheets like morphology with 40-50nm thickness and lateral size up to the certain micrometer [10,41-42]. This confirms the formation of GO by oxidation of Graphite.

The Raman spectral peaks of GO can be observed at $1609 \mathrm{~cm}$ ${ }^{1}$ and $1348 \mathrm{~cm}^{-1}$ corresponding to $\mathrm{G}$ band of $\mathrm{sp}^{2}$-hybridized carbon and $\mathrm{D}$ bands of defects or edge areas (Figure 3a). The intensity of $\mathrm{D}$ band is more as compared to $\mathrm{G}$ band which confirms the oxidation of graphite [41]. Also, the XRD peak can be observed at $10.25^{\circ}$ (001), which confirms the exfoliation of GO due to attachment of oxygenated functional groups [41-44] (Figure 3b).

Figure 3c shows the FTIR of GO and their ECF composites. It is noticed that GO exhibited broad absorption peak at $3215 \mathrm{~cm}^{-}$ ${ }^{1}$ and $3358 \mathrm{~cm}^{-1}$ corresponding to water for stretching vibration of hydroxyl group. The peaks observed at $1715 \mathrm{~cm}^{-1}, 1620 \mathrm{~cm}^{-1}$, $1041 \mathrm{~cm}^{-1}$ correspond to $\mathrm{C}=0$ stretching, unoxidized $\mathrm{sp}^{2} \mathrm{C}-\mathrm{C}$ bonds, skeletal $\mathrm{C}-\mathrm{O}$ stretching respectively, confirming the oxidation of
$\mathrm{E}_{\mathrm{f}}=$ flexural modulus of elasticity (MPa), $\Delta \sigma_{\mathrm{f}}=$ difference in flexural stress between the two strain points (MPa), $\Delta \varepsilon_{\mathrm{f}}=$ difference between two selected strain points.

The impact strength of the composites was conducted on Izod Impact tester, 293, International Equipment's, Mumbai by clamping a specimen vertically as a cantilever beam per ASTM D 256. The specimen was strucked by swing of pendulum released from a fix distance from the specimen clamp. The tests were repeated five times and average values are reported.

The surface hardness tests of composites were carried out by first placing a specimen on a hard and flat surface of Shore-D durometer. The pressure foot of the instrument was pressed onto the specimen, making sure that it was parallel to the surface of the specimen. The durometer hardness was read within 1 sec after the pressure put in firm contact with the specimen. The tests were repeated five times and mean value is reported.

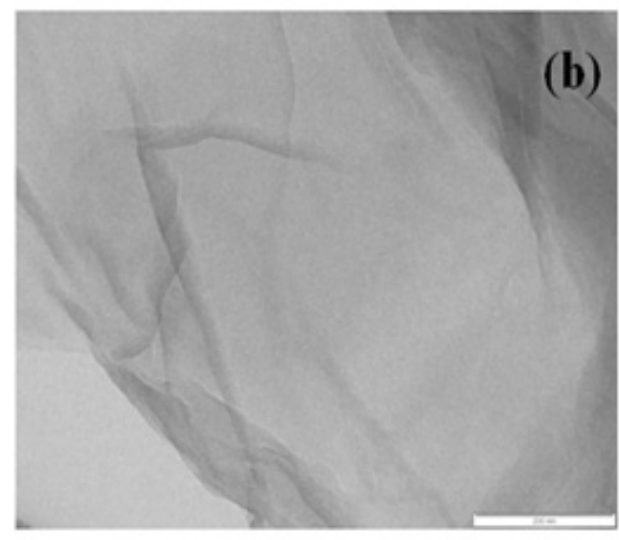

GO sheets [41-44]. The peak observed at $2918 \mathrm{~cm}^{-1}$ correspond to C-H group deformation, $1730 \mathrm{~cm}^{-1}$ for hemicellulose, $1650 \mathrm{~cm}^{-1}$ and $1242 \mathrm{~cm}^{-1}$ for C-O-C in cellulose chain while $1043 \mathrm{~cm}^{-1}$ correspond to $\mathrm{C}-\mathrm{OH}$ stretching vibration of the coir fiber $[46,47]$. For uncured epoxy resin, the absorption peaks at $3055 \mathrm{~cm}^{-1}$ correspond to symmetric stretching of oxirane groups, peak at $1178 \mathrm{~cm}^{-1}$ for C-O aromatic ring stretching, peaks at $916 \mathrm{~cm}^{-1}$ and $829 \mathrm{~cm}^{-1}$ for C-O oxirane group and aromatic absorbance respectively [48]. For ECF composite and 5.0wt.\% GO/ ECF composites, the peak at $3055 \mathrm{~cm}^{-}$ ${ }^{1}$ was absent while new peaks at $1240 \mathrm{~cm}^{-1}$ and $1029 \mathrm{~cm}^{-1}$ were present corresponding to the $\mathrm{C}-\mathrm{O}-\mathrm{C}$ of cellulose and $\mathrm{C}-\mathrm{OH}$ groups of coir fiber $[46,47]$ respectively. After curing, the peak at $916 \mathrm{~cm}^{-1}$ is diminished from the ECF composites; confirming the complete curing of epoxy resin. This is due to reaction of all epoxy groups with the hardner kept at room temperature for a week. Also, the absence of peaks at $1620 \mathrm{~cm}^{-1}$ in $5.0 \mathrm{wt}$ \% GO/ECF composites was due to the uniform dispersion of GO by CTAB treatment $[45,48]$. 

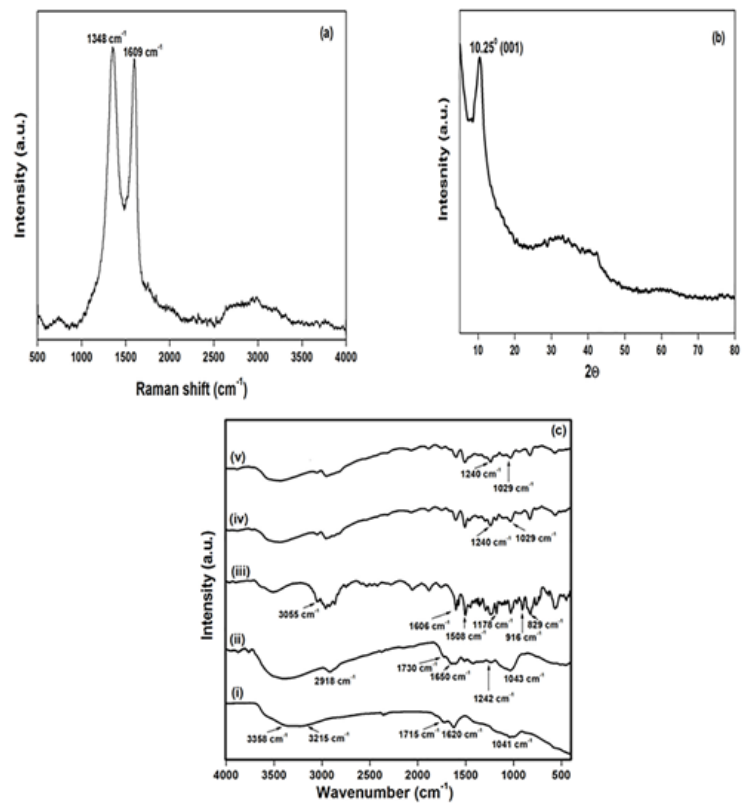

Figure 3: a) Raman spectra and b)XRD of GO; c) FTIR of (i) Coir fiber (ii) GO (iii) uncured epoxy (iv) ECF and (v) 5.0 wt.\% GO reinforced ECF composites.

\section{Mechanical properties of Graphene oxide reinforced epoxy/coir fiber (GO/ECF) composites}

Tensile strength, \% elongation at break and Young's modulus: It is observed from Figure 4a that the tensile strength increases with increase in GO concentration from $1.0 \mathrm{wt}$. \% to $5.0 \mathrm{wt}$. \% in GO/ECF composites. The neat epoxy shows the tensile strength of
$4 \mathrm{MPa}$ (Figure 4a). The maximum tensile strength (13 $\mathrm{MPa})$ was recorded for 5.0 wt. \% GO/ECF composite as compared to $6 \mathrm{MPa}$ of ECF composite; $7 \mathrm{MPa}$ of 1.0 wt.\% GO/ECF composite and $9 \mathrm{MPa}$ of $2.5 \mathrm{wt} . \% \mathrm{GO} / \mathrm{ECF}$ composite. Thus, it is proved that enrichment in the tensile strength of the ECF composites is obtained with increasing GO concentration due to proper interlocking of GO with coir fiber and epoxy resin.

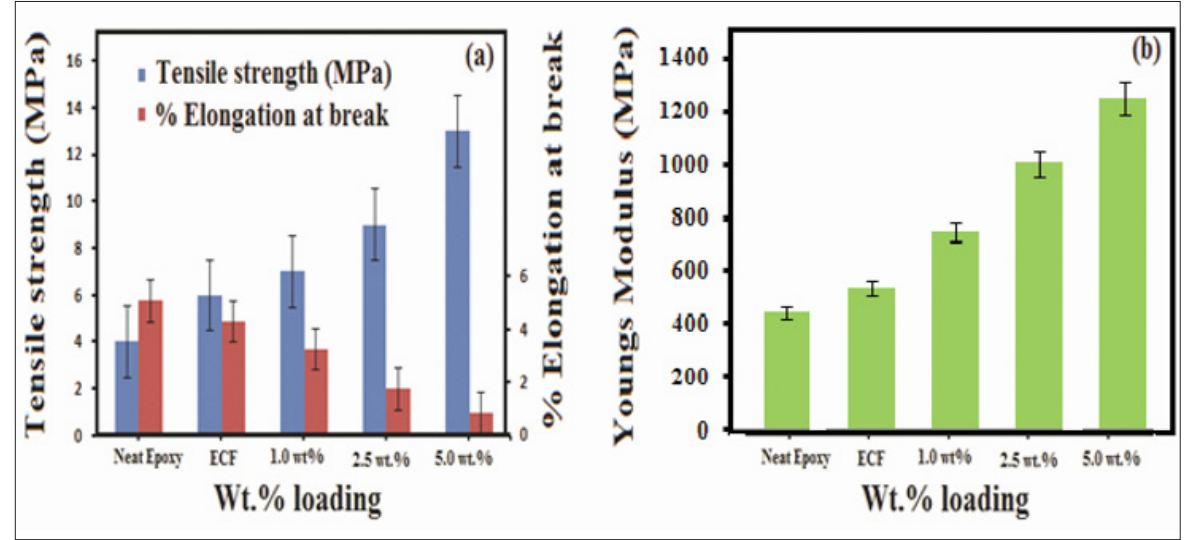

Figure 4: a) Tensile strength and \% Elongation at break b) Young's Modulus of GO reinforced epoxy/coir fiber composites.

Figure $4 \mathrm{a}$ also shows the \% elongation at break of GO/ECF composites. As compared with results of increment in tensile strength, unlikely the reverse behavior was observed for \% elongation at break. The neat epoxy shows $5.75 \%$ elongation at break as compared to 4.9, 3.7 and $2.0 \%$ elongation at break for ECF composite, $1.0 \mathrm{wt}$.\% and 2.5 wt.\% filled GO/ECF composites respectively. The lowest $1.0 \%$ elongation at break was recorded in 5.0 wt. \% GO filled ECF composite. Thus, it is confirmed that GO decreases the \% elongation at break of ECF composites in reverse way as that of tensile strength due to synergistic effect of GO on ECF.

Like tensile strength, the Young's modulus was found to increase with increasing the GO contents in ECF composite (Figure $4 \mathrm{~b})$. The neat epoxy shows Young's modulus of $443 \mathrm{MPa}$, as compared to Young's moduli of $537 \mathrm{MPa}$ for ECF composite, 750 MPa for 1.0 wt.\% GO/ECF composite and $1004 \mathrm{MPa}$ for $2.5 \mathrm{wt} . \%$ GO/ECF composite respectively. The highest Young's modulus of $1250 \mathrm{MPa}$ was recorded for $5.0 \mathrm{wt}$ \% \% GO/ECF composite. Thus, GO also improves Young's modulus of ECF composites in a similar way as that of tensile strength due to good dispersion of GO in the epoxy matrix and good compatibility with the coir fiber. Moreover, the functional groups present on the GO surface increased the degree of crosslinking as resulted in improvement in tensile property. 
Flexural strength and flexural modulus: Figure 5 shows the flexural strength and flexural modulus of GO/ECF composites. As compared to increment in tensile strength with $\mathrm{GO}$, similar behavior was observed for the flexural strength and flexural modulus in all GO/ECF composites. The neat epoxy showed the flexural strength of $23 \mathrm{MPa}$ and flexural modulus of $720 \mathrm{MPa}$ respectively. Flexural strength of 32,37 and $49 \mathrm{MPa}$, and flexural moduli of 1103,1425 and 1718MPa were obtained for ECF composite, 1.0 wt.\% GO/ECF composite and 2.5 wt.\% GO/ ECF composite respectively while maximum flexural strength of $64 \mathrm{MPa}$ and flexural modulus of 2006 MPa were recorded in ECF composites filled with 5.0 wt. \% of GO. Thus, it is proved that synergistic effect of GO resulted in an increase in flexural strength and flexural modulus of ECF composites in similar way as that of tensile strength.

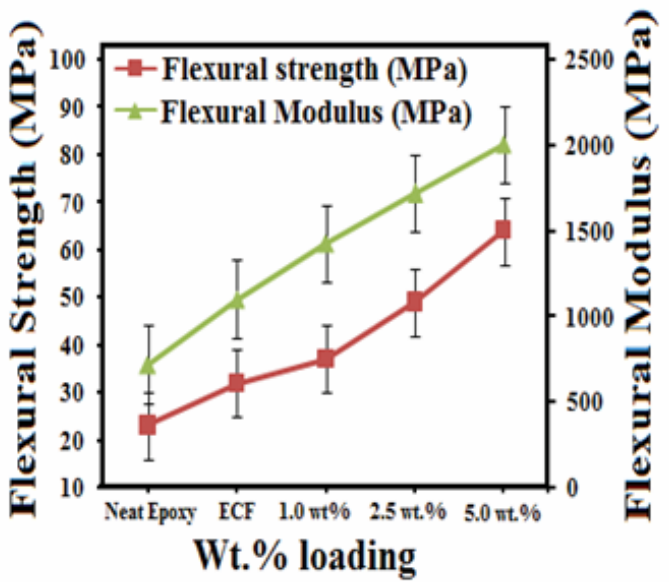

Figure 5: Flexural strength and flexural modulus of GO reinforced epoxy/coir fiber composites.

Impact strength and shore $\mathbf{D}$ hardness: The impact strength of GO/ECF composites was found to increase with increasing the GO contents, like tensile and flexural properties (Figure 6). The neat epoxy shows the impact strength of $31 \mathrm{~J} / \mathrm{m}$ as compared to 44,62 and $89 \mathrm{~J} / \mathrm{m}$ for ECF, $1.0 \mathrm{wt} . \% \mathrm{GO} / \mathrm{ECF}$ composite and $2.5 \mathrm{wt} . \% \mathrm{GO} /$ ECF composite respectively. The highest impact strength of $135 \mathrm{~J} / \mathrm{m}$ was recorded in ECF composite filled with 5.0 wt. \% GO. Thus, it is proved that the increase in GO contents is responsible for the increment in the impact strength of ECF composites.
Unlike the impact strength, opposite behavior was observed for Shore D hardness tests in G0/ECF composites (Figure 6). The neat epoxy shows the Shore-D hardness of 75 as compared to 68, 62 and 54 for ECF composite, 1.0 wt.\% GO/ECF composite and 2.5 wt.\% GO/ECF composite respectively. The lowest shore D hardness of 49 was recorded for 5.0 wt.\% GO/ECF composite. Thus, it is proved that GO decreases the brittleness of ECF composites which is responsible for the decrease in the shore D hardness of GO/ECFs.

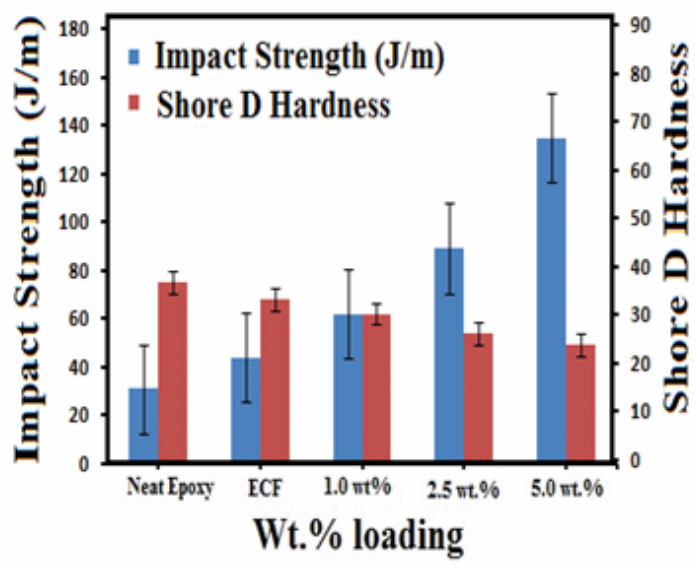

Figure 6: Impact strength and Shore D Hardness of GO reinforced epoxy/coir fibre composites.

\section{Conclusion}

GO is synthesized by improved hummmer's method and confirmed by FE-SEM, TEM, FTIR, XRD and Raman spectroscopy. FE-SEM and TEM reveal the presence of overlapped GO layer while FTIR and Raman reveal that GO has oxygen functional groups, responsible for interaction with epoxy resin and coir fiber. The GO is used as nanofiller in ECF. GO enriches the overall mechanical properties of ECF. For $5.0 \mathrm{wt}$ \% GO/ECF composite, the mechanical properties such as tensile strength, Young's modulus, flexural strength, flexural modulus and impact strength show \% enrichment up to $325,282,278,278$ and $435 \%$ respectively as compared to neat epoxy. The enrichment in tensile strength and impact strength is responsible for decrement in hardness to a percentage of 65 for 5.0 wt. \% GO/ECF composite as compared to neat epoxy. Thus, 5.0 
wt. \% GO/ECF composite shows highest mechanical properties as compared to neat epoxy and ECF composites respectively due to proper interlocking and synergistic effect of GO with coir fiber and epoxy resin, obtained due to good dispersion of GO in epoxy matrix by CTAB.

\section{References}

1. Wei J, Vo T, Inam F (2015) Epoxy/graphene nanocomposites-processing and properties : a review. RSC Advances 5: 73510-73524.

2. Wan Y, Tang L, Gong L (2014) Grafting of epoxy chains onto graphene oxide for epoxy composites with improved mechanical and thermal properties. Carbon 69: 467-480.

3. Chandrasekaran S, Sato N, Tölle F (2014) Fracture toughness and failure mechanism of graphene based epoxy composites. Composites Science and Technology 97: 90-99

4. Naldony P, Flores-Sahagun THS, Satyanarayana KG (2016) Effect of the type of fiber (coconut, eucalyptus, or pine) and compatibilizer on the properties of extruded composites of recycled high density polyethylene. Journal of Composite Materials 50(1): 45-56.

5. Qi B, Lu SR, Xiao XE (2014) Enhanced thermal and mechanical properties of epoxy composites by mixing thermotropic liquid crystalline epoxy grafted graphene oxide. eXPRESS Polymer Letters 8(7): 467-479.

6. Dash D, Samanta S, Gautam SS, Murlidhar M (2013) Mechanical characterizations of natural fiber reinforced composite materials. Advanced Materials Manufacturing and Characterization 3(1): 275-280.

7. Das G, Biswas S (2016) Physical, mechanical and water absorption behaviour of coir fiber reinforced epoxy composites filled with $\mathrm{Al}_{2} \mathrm{O}_{3}$ particulates. IOP Conf. Series: Materials Science and Engineering 115: $1-11$.

8. Yavari F, Rafiee MA, Rafiee J (2010) Dramatic increase in fatigue life in hierarchical graphene composites. ACS Applied Materials and Interfaces 2(10): 2738-2743.

9. Mishra S, Naik J B, Patil YP (2000) The compatibilising effect of maleic anhydride on swelling and mechanical properties of plant-fiberreinforced novolac resins. Composite Science and Technology 60: 17291735.

10. Wana YJ, Tang LC, Yan D (2013) Improved dispersion and interface in the graphene/epoxy composites via a facile surfactant-assisted process. Composites Science and Technology 82: 60-68.

11. Monimoy S, Pankaj T, Soumen P (2016) Thermodynamic approach to enhance the dispersion of graphene in epoxy matrix and its effect on mechanical and thermal properties of epoxy nanocomposites. Composite Interfaces 23(3): 255-272.

12. Li Z, Wang R, Young JR (2013) Control of the functionality of graphene oxide for its application in epoxy nanocomposites. Polymer 54(23): 6437-6446.

13. Qiu SL, Wang CS, Wang YT, Liu CG, Chen XY, et al. (2011) Effects of graphene oxides on the cure behaviors of a tetrafunctional epoxy resin. eXpress Polymer Letters 5(9): 809-818.

14. Edward P, Wentao Z, Matthieu G (2017) The effect of shear mixing speed and time on the mechanical properties of GNP/ epoxy composites. Applied Composite Materials 24: 301-311.

15. Adak NC, Chhetri S, Kim NH, Murmu NC, Samanta P, et al. (2018) Static and dynamic mechanical properties of graphene oxide-incorporated woven carbon fiber/epoxy composite. Journal of Materials engineering and performance 27: 1138-1147.

16. Ding R, Wang X, Jiang J (2017) Study on evolution of coating state and role of graphene in graphene-modified low-zinc waterborne epoxy anticorrosion coating by electrochemical impedance spectroscopy. Journal of materials engineering and performance 26: 3319-3335.
17. Mohan TP, Kanny K (2018) Mechanical properties and failure analysis of short kneaf fiber reinforced composites processed by resin casting and vacuum infusion methods. Polymer and Polymer Composites 26(2): 189-204.

18. Murali K, Vigneshwaran T, Johnson G (2016) Experimental study on structural characterization of biocomposites. Polymers \& Polymer Composites 24(7): 481-487.

19. Mishra S, Naik JB (2005) Studies on electrical properties of natural fiber: HDPE composites. Polymer-Plastics Technology and Engineering 44: 687-693.

20. Mishra S, Naik J B (2005) Effect of treatment of maleic anhydride on mechanical properties of natural fiber: polystyrene composites. Polymer-Plastics Technology and Engineering 44: 663-675.

21. Poutrel QA, Wang Z, Wang DC (2017) Effect of pre and post-dispersion on electro-thermo-mechanical properties of a graphene enhanced epoxy. Appl Compos Mater24: 313-336.

22. Chang L, Zhang Z, Breidt C (2004) Impact resistance of short fibre/ particle reinforced epoxy. Applied Composite Materials 11(1): 1-15.

23. Mishra S, Naik JB (2007) Esterification effect of maleic anhydride on swelling properties of natural fiber/high density polyethylene composites. Journal of Applied Polymer Science 106(4): 2571-2574.

24. Mishra S, Naik J B, Patil Y (2004) Studies on swelling properties of wood/polymer composites based on agro-waste and novolac. Advances in Polymer Technology 23(3): 1-5.

25. Kavalastrahiremath SC (2016) Evaluation of tensile and flexural properties of coconut coir and coconut shell powder reinforced epoxy composites. International Journal of Engineering Research and Technology 5(2): 36-40.

26. Nagaraja G, Basavaiah C (2011) Export of coir and coir products from india : an analysis. Indian Development Review 9(1) : 11-18.

27. Luza FS, Monteiroa SN, Limaa ES (2017) Ballistic application of coir fiber reinforced epoxy composite in multilayered armor. Materials Research, pp. 1-6.

28. Shimpi NG, Verma J, Mishra S (2010) Dispersion of nano $\mathrm{CaCO}_{3}$ on PVC and its influence on mechanical and thermal properties. Journal of composite materials 44(2): 211-219.

29. Mishra S, Shimpi NG, Mali A (2012) Investigation of photo-oxidative effect on morphology and degradation of mechanical and physical properties of nano $\mathrm{CaCO}_{3}$ silicone rubber composites. Polymer for advanced technologies 23(2): 236-246.

30. Mishra S, Shimpi N G (2007) Effect of the variation in the weight percentage of the loading and the reduction in the nanosizes of $\mathrm{CaSO}_{4}$ on the mechanical and thermal properties of styrene-butadiene rubber. Journal of Applied Polymer science 104 (3): 2018-2026.

31. Mishra S, Sonawane S, Chitodkar V (2005) Comparative study on improvement in mechanical and flame retarding properties of epoxy$\mathrm{CaCO}_{3}$ nano and commercial composites. Polymer-Plastic Technology and Engineering 44(3): 463-473.

32. Marcano DC, Kosynkin DV, Berlin JM (2010) Improved synthesis of graphene oxide. ACS Nanoletters 4(8): 4806-4814.

33. Sun Y, Shi G (2013) Graphene/polymer composites for energy applications. Journal of Polymer Science Part B: Polymer Physics 51(4): 231-253.

34. Hansora DP, Shimpi NG, Mishra S (2015) Graphite to graphene via graphene oxide : An Overview on synthesis, properties, and applications. Journal of Materials 67(12): 2855-2868.

35. Bari P, Lanjewar S, Mishra S (2016) Influence of the coupling agent and graphene oxide on the thermal and mechanical behavior of tea dustpolypropylene composites. Journal of Applied Polymer Science 133(4): $1-10$. 
36. Khobragade PS, Hansora DP, Naik JB (2017) Physico-mechanical properties of nano polystyrene (nPS) decorated graphene oxide (GO)epoxy composites. Polymer International 66: 1402-1409.

37. Rana VK, Choi M, Kong J (2011) Synthesis and drug-delivery behavior of chitosan-functionalized graphene oxide hybrid nanosheets. Macromolecular Material Engineering 296: 131-140.

38. Xu Y, Shi G (2011) Assembly of chemically modified graphene : methods and applications. Journal of Material Chemistry (10): 3311-3323.

39. Mishra S, Hansora D P (2017) Graphene nanomaterials: Fabrication, properties and applications. CRC press.

40. Wojtoniszak M, Mijowska E (2012) Controlled oxidation of graphite to graphene oxide with novel oxidants in a bulk scale. Journal of Nanoparticle Research 14(11): 1248-1255.

41. Pathak AK, Borah M, Gupta A (2016) Improved mechanical properties of carbon fiber/graphene oxide- epoxy hybrid composites. Composites Science and Technology 135: 28-38.

42. Jain R, Mishra S (2016) Electrical and electrochemical properties of graphene modulated through surface. RSC Advances 6: 27404-27415.
43. Khobragade PS, Hansora DP, Naik JB (2017) Effect of multilayered nanostructures on the physico- mechanical properties of ethylene vinyl acetate-based hybrid nanocomposites. Polymer Composites 39(10): 3519-3527.

44. Khobragade PS, Hansora DP, Naik JB (2016) Preparation and analysis of multi-layered hybrid nanostructures. Applied Clay Science 132: 668674.

45. Bharadiya P, Singh M, Mishra S (2019) Influence of graphene oxide on mechanical and hydrophilic properties of Epoxy/Banana fiber Composites. Journal of Material 71(2): 838-843.

46. Eldho Abraham, Deepa B, Pothen LA, Cinthil J, Thomas S (2013) Environmental friendly method for the extraction of coir fibre and isolation of nanofibre. Carbohydrate Polymers 92(2): 1477-1483.

47. Cheila GM, Iara C de Miranda (2009) Characterization of sugarcane and coconut fibers by thermal analysis and FTIR. J Therm Anal Calorim 97: 661-665.

48. Sagar TC, Mykanth RM, Singh RRK, Yu B, Zhao XL, et al. (2014) Defence Science Journal 64(3): 314 